\title{
Medical response to male same-sex sexuality in western India: An exploration of 'conversion treatments' for homosexuality
}

Ketki Ranade

Follow this and additional works at: https://knowledgecommons.popcouncil.org/departments_sbsr-rh

Part of the Demography, Population, and Ecology Commons, Family, Life Course, and Society Commons, and the International Public Health Commons How does access to this work benefit you? Let us know!

\section{Recommended Citation}

Ranade, Ketki. 2009. "Medical response to male same-sex sexuality in western India: An exploration of 'conversion treatments' for homosexuality," Health and Population Innovation Fellowship Programme Working Paper no. 8. New Delhi: Population Council. 

This report is the result of a project entitled "Medical response to male same-sex sexuality in Western India An exploration of 'Conversion Treatments' for homosexuality," undertaken as part of the Health and Population Innovation Fellowship (HPIF) awarded to the author in 2006.

The HPIF programme is administered by the Population Council, New Delhi and is a continuation of the MacArthur Foundation's Fund for Leadership Development (FLD) fellowship programme that continued over the period 1995 to 2004. The Council is grateful to the MacArthur Foundation for its support to this programme.

The HPIF programme aims to support mid-career individuals who have innovative ideas, leadership potential, and the capacity to help shape policy and public debate in the field of population, reproductive health and rights in general, with a focus on two priority themes maternal mortality and morbidity, and the sexual and reproductive health and rights of young people. Since the transfer of the programme to the Population Council through 2006, a total of 17 individuals have been supported under the HPIF programme.

\section{For additional copies of this report, please contact:}

Ketki Ranade

Bapu Trust, Plot No. 9;

Survey No. 50/4,

'Kapil Villa', Ground Floor,

Satyanand Hospital Lane,

Kondhwa Khurd,

Pune - 411048
Population Council

Zone 5A, Ground Floor

India Habitat Centre

Lodi Road, New Delhi 110003

Phone: 011-24642901/02

email: info-india@popcouncil.org

Web site: http://www.popcouncil.org/asia/india.html

The Population Council is an international, non-profit, non-governmental organisation that seeks to improve the well-being and reproductive health of current and future generations around the world and to help achieve a humane, equitable and sustainable balance between people and resources. The Council conducts biomedical, social science and public health research, and helps build research capacities in developing countries.

\section{Copyright (C) 2009 Ketki Ranade}

About the author: Ketki Ranade has an M.A. in medical and psyhciatric social work from Tata Institute of Social Sciences, Mumbai and an MPhil in psychiatric social work from NIMAHNS, Bangalore. She has been working since the last six years as a psychotherapist, researcher and trainer in the field of mental health. Her area of interest includes social marginalisation and mental health, specifically sexual minorty mental health, gender and mental health. She is currently based at Bapu Trust, Pune, an NGO working in the area of mental health research, service and advocacy.

Suggested citation: K. Ranade. 2009. "Medical response to male same-sex sexuality in Western India: An exploration of 'Conversion Treatments' for homosexuality," Health and Population Innovation Fellowship Programme Working Paper, No. 8. New Delhi: Population Council.

\section{(P) Population Council}




\section{Medical response to male same-sex sexuality in Western India}

\section{AN EXPLORATION OF 'CONVERSION TREATMENTS' FOR HOMOSEXUALITY}

Ketki Ranade

Fellow

Health and Population Innovation Fellowship Programme 


\section{Contents}

Introduction 1

What do we know about conversion therapy? 3

The Indian context 4

Study design 6

Limitations 7

Profile of the study participants 8

What determines the use of conversion therapy? 11

Ego-dystonic homosexuality 11

Perceived environmental cause of homosexuality 12

'Superficial' homosexuality 14

Adequate motivation to change 15

What are the methods used? 16

Fantasy building 16

Advice-giving 17

Enhancing heterosexual sexual performance 18

What defines successful therapy? 20

Discussion

Summing up and recommendations 25

Summing up 25

Recommendations 25

References 26

Acknowledgements 29 


\section{List of Tables}

Table 1: Profession and location of study participants 8

Table 2: Therapeutic approaches used by health care providers 9

Table 3: Profession of health care providers using conversion methods 10

Table 4: Perceived causes of homosexuality as reported by health care providers 13

iv $\mid$ Ketki Ranade 


\section{Introduction}

Until the mid-1950s, sexual orientation hardly qualified as a subject of scientific study. Homosexuality was listed as a mental disorder by the American Psychiatric Association (APA) in their Diagnostic and Statistical Manual of Psychiatric Disorders (DSM) (APA, 1952), branded a sexual deviation by mental health professionals, and condemned by religion and society as 'immoral' and 'abnormal'. Consequently, homosexuals were, by and large, invisible.

In 1957, Evelyn Hooker's pioneering study, challenging the prevalent belief that homosexuality is an illness and deviancy, led to the accumulation of a large body of empirical evidence (Hooker, 1957). As a result, the past three decades have witnessed a remarkable transformation in the status of homosexuality. In 1973, the APA declassified homosexuality as a mental disorder from the DSM (APA Position Statement, 1973) and in 1987, also deleted its clinical sub-variant, 'ego-dystonic homosexuality', from the DSM (DSM-III-R) and from American textbooks of Psychiatry (APA, 1987). Subsequently, in 1992, the World Health Organisation (WHO) removed homosexuality from its list of mental illnesses ICD-10 (International Classification of Diseases) (WHO, 1992). Just as influential in the APA's decision was the gay liberation movement which emerged in 1969 in the US and, backed by scientific evidence, resulted in the decriminalization of homosexual behavior in 1974.

By contrast, in India, despite a rich and long history of sexual diversity (Vanita and Kidwai, 2000), homosexuality is not only regarded as an abnormality but a crime under Section 377 of the Indian Penal Code (IPC). This law, described as a British colonial anti-sodomy law passed in the early 1860s ('Voices Against 377', 2005), can be seen as representing a Christian religious view of sin in understanding sexuality, a view that is neither consonant with Indian history nor with current international medical and legal principles (Yogyakarta Principles, UN, 2006). On the health front, Indian scholars of psychiatry and psychology have "preserved an almost complete silence on the subject of homosexuality' (Parekh, 2003). There has been very little debate or theorizing on sexual orientation and the shift of homosexuality from abnormality to normality has been passively accepted by the medical community. In fact, neither the inclusion of homosexuality or ego-dystonic homosexuality as mental disorders in the APA classification nor their subsequent deletion, has provoked any dialogue on the cultural relevance of these diagnoses.

Again, unlike the West, the gay movement in India is as yet nascent. Nevertheless, in recent years, slowly changing attitudes and the need to control HIV/AIDS have prompted several NGOs to demand legalisation or at least de-criminalisation of homosexuality. Citing statistics to show that 8 per cent of the gay population in India is afflicted with HIV/AIDS as against one per cent of the general population, the National AIDS Control Organisation, a government body, has submitted an affidavit before the high court for amending Section 377 which, by stigmatising homosexuality, undermines the ability of the government to reach out to those who are most vulnerable (The Times of India, 2006). 
An article on Section 377 (Economic and Political Weekly, October 2008) states that the Delhi High Court is currently hearing several petitions asking for the reading down of Section 377. One of the first filed by Naz Foundation (India) Trust (an NGO working on health), seeking a reading down of Section 377 on the ground that it prevents health workers from openly working with gays on prevention of HIV/AIDS, was turned down by the court saying that it had no locus standi on the issue. Naz appealed to the Supreme Court which has directed the Delhi High Court to hear the case. More recently, in August 2008, the Union health minister recommended that Section 377 should be repealed "if HIV/AIDS prevention, care and treatment programmes are to succeed." However, the Union Ministry of Home Affairs, the main custodian of the law, maintains that homosexuality is a "disease" and is "immoral"; it also argues that the Section reflects the "will of the people". In the circumstances, the law continues to exist and is often used to harass homosexuals (People’s Union for Civil Liberties-Karnataka Chapter, 2001).

Prior to the declassification of homosexuality, Western literature is replete with the attempts of medical, psychotherapeutic and religious practitioners to alter same-sex orientation. Referred to as "conversion therapy", such attempts include a variety of methods intended to change a homosexual orientation to a heterosexual one (Haldeman, 1994). Following the APA decision, however, mainstream medical organisations no longer endorse conversion therapy though it continues to be supported by some major religious organisations and professionals (Chandran, 2006).

Unfortunately, apart from a few sporadic reports or articles in the print media, there is very little systematic study or documentation of the views of Indian health care professionals regarding homosexuality, or the use and outcomes of conversion treatments. Given that conversion as a form of therapy for homosexuality is used by many practitioners in India and the paucity of scientific data on conversion therapy, this report aims at exploring its use by health care providers in Western India to treat homosexuals, the criteria used for selecting clients for conversion therapy, the types of therapies employed, and perceived outcomes of such therapies. Finally, it suggests recommendations for enabling health care providers to employ mainstream thinking in their treatment of homosexual individuals in India. 


\section{What do we know about conversion therapy?}

The use of conversion techniques presupposes that homosexuality is pathological or problematic and warrants treatment or repair. The APA defines conversion therapy as "psychiatric treatment... which is based upon the assumption that homosexuality per se is a mental disorder or based upon the a priori assumption that a patient should change his/her sexual homosexual orientation" (APA, 2000) while the American Psychological Association (American Psychological Association, 2008) defines it as therapy aimed at changing sexual orientation. Both these organisations also use the term 'reparative therapy' introduced by Nicolosi in 1991 (Nicolosi, 1991) as a synonym for conversion therapy in general.

The evolution of conversion therapy can roughly be traced through three periods: an early Freudian period, a period of mainstream approval of conversion therapy, and a period following the declassification of homosexuality as a mental illness when the mainstream medical profession disowned it (Yoshino, 2002-01; Drescher, 1998).

Conversion therapy subsumes a wide variety of psychoanalytical, behavioral, biological and religious methods. During the early Freudian period, measures such as castration, sterilisation and hypnosis were the methods of choice (Katz, 1976). The three decades between Freud's death in 1939 and the birth of the gay rights movement in 1969, a period during which conversion therapy was approved by most of the psychiatric establishment in the US, witnessed a diversity of approaches. The interventions included psychoanalysis, prayer and spiritual interventions, electric shock, nausea-inducing drugs/ aversion therapy, hormone therapy, surgery, and various adjunctive behavioural interventions including masturbatory reconditioning, rest, visits to prostitutes and so on (Murphy, 1992). However, by the mid-1970's, subsequent to the de-pathologisation of homosexuality, these methods were largely abandoned by the mainstream health establishment. Despite this, some professionals offer "a possibility of change" for homosexuals who are unsatisfied with their sexual orientation rather than promoting cures; often emphasising the reduction of the individual's homosexual desires rather than eliminating them completely (see, for example, Throckmorton, 2003-2004).

Conversion therapists have different views on what constitutes effective treatment. While religious groups often encourage celibacy for their "ex-gay" followers, interpreting lack of sexual contact as successful treatment, many behavior-change techniques define "success" as suppression of homoerotic response (reducing or eliminating homosexual behavior rather than in creating or increasing heterosexual attractions) or mere display of physiological ability to engage in heterosexual intercourse. Neither outcome adopts the complex set of attractions and feelings that constitute sexual orientation. Even so, if some individuals eventually do make such a change, there is no evidence for a cause-and-effect relationship, and such therapies would remain ethically questionable (Herek, 1999).

Conversion therapy has been discredited on several grounds. Almost all medical organisations maintain that there is little or no empirical evidence supporting the efficacy 
of these treatments. Most studies that claim success often have serious limitations and/or study design flaws, including sampling biases, absence of comparison groups, exclusive reliance on self-reported or therapist-reported outcome data, low success rates, varying definitions of success, and limited follow-up data (Haldeman, 1994, 2002; Morrow and Beckstead; 2004; Tozer and McClanahan, 1999). Besides, most of the studies define sexual orientation only in behavioural terms ignoring the biological, gender based, social and emotional components integral to sexual orientation. The fundamental objection to conversion therapy that if human desire is seen as being diverse, varied and plural, the notion of converting back to something does not arise, has been aptly summarised by Halpert in the title of his review; 'If it ain’t broke, don’t fix it' (Halpert, 2000).

Thus, while numerous researchers and clinicians have claimed to re-orient homosexual individuals (Nicolosi, Byrd and Potts, 2000; Throckmorton, 1998, for a review), the critical methodological problems mentioned above cast much doubt on the authenticity of their conclusions (Haldeman, 1994). The APA has stated that success stories and harm stories are anecdotal, and that "there are no scientifically rigorous outcome studies to determine either the actual efficacy or harm of "reparative" treatments (APA Position Statement, 2000).

In addition to the scepticism over efficacy, serious concerns have been expressed over the safety and ethics of conversion therapy, and harmful effects such as increased guilt, anxiety, low self-esteem, sense of personal failure, suicidal ideation and temporary or long-term sexual dysfunction have been reported (Haldeman, 1994).

Concerns have also been expressed over its unethical practice and potential for reinforcing societal prejudices and pathological views of homosexuality. Consequently, in 1998, through a resolution, the APA opposed any psychiatric treatment including conversion therapy which is "based upon the assumption that homosexuality per se is a mental disorder or based upon the a priori assumption that a patient should change his/her homosexual orientation” (APA Position Statement, 1998). Furthermore, respecting the client's right to self-determination, most mainstream health organizations including the APA have issued ethics guidelines or statements warning of possible harm and the potential of serious safety risks resulting from participation in conversion therapies, and in 2000, the APA called for more scientific research to determine the risks and benefits involved, and until such research is available, recommended that "ethical practitioners refrain from attempts to change individuals' sexual orientation (APA Position Statement, 2000).

In view of the mainstream consensus regarding the efficacy, safety and ethical concerns of conversion therapy, traditional conversion approaches have been replaced by more "affirmative" approaches to help the individual to overcome societal prejudices against homosexuality and lead a satisfying life as a homosexual.

\section{The Indian context}

In India, medical practitioners, by and large, consider ego-dystonic homosexuality as a condition warranting treatment. In this clinical sub-variant of homosexuality, the sexual 
preference of the individual is not in doubt but the individual wishes it were different and seeks treatment. In such a case, treatment is warranted. By contrast, in ego-syntonic homosexuality, the individual is comfortable with his or her sexual preference or gender identity, and treatment is not warranted.

The People's Union For Civil Liberties (PUCL) reports that doctors will often diagnose the patient as ego-dystonic even if the patient is ego-syntonic. The PUCL further reports that though it is claimed that a person's ego-syntonicity or dystonicity is determined clinically, a reputed doctor at a prominent Bangalore hospital has conceded that a person's distress with his homosexuality may be due to different factors like the pressure to get married or the need to conform to culturally appropriate sexual practices (People's Union For Civil Liberties-Karnataka Chapter, 2001).

Due to lack of adequate research, data regarding the number of people treated by and the outcomes of conversion therapy are sorely lacking. In fact, the first reported case was a complaint filed before the Delhi High Court in 2001 by the Naz Foundation (India) Trust on the ground that it violated the fundamental rights of a patient who was being treated for (change of) homosexuality with counseling and drugs over a four-year period at the All India Institute for Medical Sciences, New Delhi (Narrain, 2002). A paper on the use of behavioral modification techniques reports that eight out of thirteen male homosexuals showed a shift to heterosexual adaptation that was maintained during a six-month and one-year follow-up (Pradhan, Ayyer and Bagadia, 1982).

Thus, in the context of a society where there is scant information about same-sex desires and relationships and little dialogue among the medical community or research on the subject, homosexuals continue to be subjected to a wide range of conversion treatments. There is no evidence either that these practitioners follow prescribed norms for treating homosexuality or use standard treatment protocols and prescribed ethics guidelines. Likewise, there is no documentation of the 'cures' for homosexuality offered by practitioners of the traditional and informal systems of medicine who cater to the health problems, including sexual problems, of a substantial population. 


\section{Study design}

The study was conducted in the metropolitan cities of Mumbai and Pune in Maharashtra State, India, between April 2007 and January 2008. An exploratory-descriptive, qualitative research design was used.

The health care providers originally selected for the study comprised psychiatrists, sexologists, gynaecologists, dermatologists, urologists and counsellors who had been consulted by homosexual clients. Based on its objectives and literature review, the research design initially intended to target only psychiatrists, sexologists and gynaecologists: psychiatrists because psychiatry, as a branch of medicine, has been historically engaged with the question of homosexuality as a perversion or normal variation and thereby its treatment or acceptance; sexologists by dint of their being medical professionals specialising in sex and sex therapy, and gynaecologists because literature suggests that lesbian and bisexual (LB) women are likely to seek their services. However, subsequently it was decided to extend it to other health care providers such as dermatologists, urologists and counsellors because early field experience and key informant interviews indicated that a substantial number of homosexual men also consult these categories of care givers.

The health care providers were identified by purposive selection. The sample was derived by sending out 525 letters soliciting participation to the membership of professional bodies of psychiatrists, gynaecologists and obstetricians in Mumbai and Pune. The poor response to the letters was followed up by telephone calls as a result of which 30 psychiatrists, gynaecologists and dermatologists were enrolled. Sexologists and urologists were contacted through information received from key informants while counsellors who had treated homosexual individuals joined the study in response to a call posted on e-groups such as the 'Counsellor's Association of India', a group of mental health professionals in India. Finally, 40 health care providers from the two cities emerged as participants.

A semi-structured interview schedule was designed, consisting of both open- and closedended questions. It comprised sections on the background of the health care providers, practice-related information, their knowledge of sexuality in general and homosexuality in particular, and their attitudes towards homosexuality.

Data were collected by way of a one-time, 45 to 90 minute interview. Oral consent was sought from each health care provider prior to the interview. The interview team consisted of an interviewer and a note-taker. Field notes were expanded and computerised on the day of the interview itself. Data analysis of coded text segments was performed with the computer software package MAX QDA version 2k1 R030801 (C 1995-2001 Udo Kuckartz Berlin). 


\section{Limitations}

The sample comprised 40 practitioners across six categories of health care providers in the two cities. Thus, a small sample is one of the limitations of the study. Moreover, since the sample was drawn by purposive sampling, the findings are representative of the health care providers interviewed and cannot be generalised to the larger health care community in these cities or in other parts of India. A further weakness of the study is that the limited time available for data collection did not permit follow-up interviews which would have provided richer descriptions of the treatments and experiences of respondents. 


\section{Profile of study participants}

As seen in Table 1, the health care providers were more or less equally distributed between the two cities both by number (Mumbai: 19 and Pune: 21) and profession. Together they comprised 19 psychiatrists, four sexologists, eight dermatologists, three gynaecologists, five counsellors and a urologist.

Table 1:

Profession and location of study participants $(\mathrm{N}=40)$

\begin{tabular}{|l|c|c|}
\hline Specialist & Pune & Mumbai \\
\hline Psychiatrist & 10 & 9 \\
Sexologist & 2 & 2 \\
Dermatologist & 4 & 4 \\
Gynaecologist & 2 & 1 \\
Counsellor & 2 & 3 \\
Urologist & 1 & 0 \\
Total & 21 & 19 \\
\hline
\end{tabular}

The category 'sexologist' included medical practitioners who had graduated in medicine (MBBS degree) and held a postgraduate qualification in dermatology, psychiatry, radiology or a course in sexual medicine from an overseas university. Irrespective of their educational background, all the health care providers had listed themselves as 'currently practising sexologists' or 'clinicians working with sexual medicine'.

Of the 40 health care providers, 28 were male and 12 were female. They were between 24 and 86 years of age and had an experience range of 9 months to 50 years. Most $(\mathrm{N}=32)$ of the health care providers were associated with private hospitals apart from having a private practice; 14 were also attached to public hospitals and NGOs engaged in mental health activities (including running a rehabilitation centre, day care centre and/or halfway home). Four of the five counsellors worked with NGOs providing services to lesbian, gay, bisexual and transgender persons.

The treatment approaches employed by the health care providers can be broadly categorised into two main groups: (1) conversion therapy for homosexuality, and (2) other therapies for symptoms presented by the client, either linked or unrelated to the client's homosexuality. In keeping with its objectives, this report explores only the first approach in detail that is, the treatment attempts of health care providers who used conversion therapy. 
The majority $(\mathrm{N}=34)$ of the health care providers reported that their clients were predominantly male homosexuals. In fact, when asked whether they had been consulted by homosexual clients, they associated the word 'homosexual' only with 'male homosexuals' and passed over descriptions of female homosexuals. Eliciting information about lesbian clients required special probing. It is important to note, therefore, that this report describes the use of conversion therapies administered to male homosexuals alone except in one instance where information about lesbian clients was available.

Table 2 shows that close to half $(\mathrm{N}=18)$ of the 40 health care providers were using some form of conversion therapy to help a homosexual person convert to a heterosexual one. Three others reported that they no longer practiced it because they doubted its efficacy; two of them also said that they would not consider it "right to treat homosexuality per se." For instance, a 43-year-old, female psychiatrist from Mumbai said:

"There was this guy.... this must be years ago, maybe at least 10 years ago. He was a doctor's son. The doctor told me that he is gay and he wanted his son to be converted. So, at that time, I gave him some behaviour therapy. He even got married after that. But it obviously did not work out... I always give this example to parents who come and ask me to convert their children. The idea is to support your children, not convert them. It would be a shock to you. It may not be acceptable to you. I can help you cope with those difficulties. But I just can't convert the child, it would simply not be right".

\section{Table 2:}

Therapeutic approaches used by health care providers $(\mathrm{N}=40)$

\begin{tabular}{|l|c|c|c|}
\hline \multirow{2}{*}{ Type of therapy } & \multicolumn{2}{|c|}{ Conversion } & $\begin{array}{c}\text { Other than } \\
\text { conversion }\end{array}$ \\
\cline { 1 - 3 } & Ever users & Current users & \\
\hline $\begin{array}{l}\text { Number of health } \\
\text { care providers }\end{array}$ & 21 & 18 & 19 \\
\hline
\end{tabular}

The remaining (19) health care providers claimed that they focused on the psychological symptoms for which the client sought help; eleven of them reported working with the client or the client's family to help enhance acceptance of homosexual orientation.

Interestingly, the 18 health care providers who used conversion methods, administered supportive treatments for some of their clients. It appears then that these health care providers employed specific criteria to decide which of their clients needed conversion therapy as distinct from those who required some form of supportive therapy.

Also of interest is the finding that five of the 19 health care providers did not consider homosexuality as a disorder. They responded to the question of the probable cause of homosexuality with statements or counter questions such as: 
"Looking for a cause for homosexuality is irrelevant."

"Asking what causes homosexuality is like asking what causes the colour

of one's eyes."

"Why do I like to wear earrings?"

"Looking for a cause implies abnormality; do we ask what causes life?"

Or, "How often do we ask what causes heterosexuality? We just accept it."

Table 3 presents a profession wise distribution of the health care providers who used conversion therapy.

\section{Table 3:}

Profession of health care providers using conversion methods $(\mathrm{N}=21)$

\begin{tabular}{l|c|c|}
$\begin{array}{l}\text { Profession of } \\
\text { health care } \\
\text { provider }\end{array}$ & $\begin{array}{c}\text { Total number of } \\
\text { health care } \\
\text { providers }\end{array}$ & $\begin{array}{c}\text { Number of health } \\
\text { care providers who } \\
\text { used conversion }\end{array}$ \\
\hline Psychiatrist & 19 & $12 *$ \\
Sexologist & 4 & 3 \\
Dermatologist & 8 & 3 \\
Gynaecologist & 3 & 2 \\
Counsellor & 5 & 0 \\
Urologist & 1 & 1 \\
Total & 40 & 21 \\
\hline
\end{tabular}

* 3 psychiatrists reported having discontinued the practice of conversion therapy.

As can be seen from Table 3, psychiatrists, gynaecologists and sexologists were more likely to use conversion techniques than those who practiced other specialities. Thus, the majority of the psychiatrists (12 of the 19 psychiatrists, three reporting discontinuation of conversion therapy since), gynaecologists (two of the three), and sexologists (three of the four) offered conversion therapy while fewer dermatologists (only three of the eight) and none of the five counsellors did so. The following sections of this report are confined to the 18 health care providers who were practicing conversion therapy at the time of the interview.

Most of the psychiatrists and sexologists among the 18 health care providers reported the use of several techniques, often behavioural, to change their patient's sexual orientation. The interventions included the use of heterosexual imagery, fantasy building, creative visualisation and cognitive behaviour therapy. On the other hand, the remaining six health care providers employed methods such as "advice" and information-giving, suggesting thereby that these categories of care givers lacked training in specific conversion techniques. 


\section{What determines the use of conversion therapy?}

Interestingly, as was seen from Table 2 above, the health care providers appeared to be able to determine whether a client would "benefit from" conversion therapy or from supportive (non-conversion) therapy and/or counselling of her/his family members. Clients can be grouped under four broad categories of criteria reported by the health care providers to decide who warranted conversion therapy - those who were diagnosed as ego-dystonic, those whose homosexuality was perceived to have been caused largely by environmental factors, those who were diagnosed as 'superficially' homosexual, and those who possessed adequate motivation to change their sexual orientation.

\section{Ego-dystonic homosexuality}

Six of the nine psychiatrists cited the distinction between ego-syntonic homosexuality and ego-dystonic homosexuality as a criterion for determining the eligibility of a client for conversion therapy. Thus, the health care providers viewed ego-dystonic homosexuality or homosexuality associated with feelings of alienation from or distress about one's sexual identity to be indicative of conversion therapy while ego-syntonic homosexuality wherein the individual is comfortable with his homosexual identity did not require a change in orientation. These views are reflected in the following quotes:

"There was this one person who was very distressed with his homosexuality and he came and told me, 'I don't want it. I want to be able to live like any other normal person and get married, have a family and so on. He was what we call a case of ego-dystonic homosexuality...” (50 years, male, Psychiatrist, Pune)

'I first ask the patient if he wants to continue as a homosexual. If he says' yes', then I tell him about the consequences like social pressure and stress, and I tell the parents that it's [homosexuality] not an illness, it's just an attraction. I also tell them that it doesn't exist in our diagnostic category. It has been removed from the $D S M-I V$ [classification of mental disorders]; so homosexuality is not a 'diagnosis'. [But] if he doesn't want to continue with it [homosexuality], I tell him about my treatment. I personally don't treat it if it's not ego-dystonic, and because of family and societal pressure..." (38 years, male, Psychiatrist, Pune)

“...There are two types of homosexuals, ego-alien and ego-syntonic. Those who are ego-alien require treatment but those who are ego-syntonic are as fine as what we call 'normal sexuality'. They are comfortable with it [homosexuality]. So what can anyone do about it?” (57 years, male, Psychiatrist, Mumbai)

"I try to assess if it [homosexuality] is dystonic or syntonic. In syntonic cases, there is no point in giving treatment, But if the patient is dystonic, he looks around in trains, urinals and places like that. For syntonics, there are groups they can go to and... if it is ego-syntonic, what is there to treat? It is very difficult to treat...” (45 years, male, Psychiatrist, Mumbai) 
The health care providers believed that some homosexual individuals are comfortable with their sexual orientation while others are not. Furthermore, they considered individuals who are not comfortable with their sexual identity, for whatever reason, as likely candidates for conversion therapy while those who were comfortable were considered to possess "normal sexuality", not warranting a change in sexual orientation. Conspicuously, the health care providers did not seem to see a role for themselves in helping individuals understand the source of their discomfort/dystonicity, that is, whether the distress is an inherent discomfort with one's sexuality or is located outside the individual as a problem of social prejudice. Equally, health care providers did not mention the need to help clients to achieve comfort with their sexuality or to develop an integrated identity as part of the care and treatment model.

\section{Perceived environmental cause of homosexuality}

The perceived cause of homosexuality or why the individual turned to homosexuality was another criterion that was used to identify clients requiring conversion therapy. As can be seen from Table 4, the most cited cause (by eight of the 18 health care providers) of homosexuality focused on experiences in 'male only' environments such as prisons, military sites and boys' boarding schools along with the non-availability of opposite sex partners.

A second category of perceived causes mentioned by an almost equal number of health care providers $(\mathrm{N}=7)$ involved environmental factors such as childhood same-sex exploration, sexual abuse experienced in childhood and past aversive sexual experiences.

That homosexuality ascribed to environmental factors was used to justify the administration of conversion therapy is reflected in the following quotes:

A sexologist from Pune while talking about her lesbian clients said,

"I check if it [homosexuality] is because of obsession or compulsion, or because they never had any experience [of heterosexual contacts]. I ask them not to be prejudiced about heterosexual relationships. I ask them to be more comfortable with heterosexual contacts. Is it that they don't want it [heterosexual contact] because they have found their comfort zone? One hears that the first sexual encounter with a man is always painful; so, could it be because they are afraid of childbearing? We don't know if they have such fears or whether they are really not attracted to men. People who have had stern fathers or... they refuse to get attached to men. In that case, is it because they are afraid of men?... When they come for counselling, we need to confirm what it [homosexuality] is due to..."

(60 years, female, Sexologist, Pune)

"I try to find out how homosexuality began - was it always there, was it through play, was it some aversive experience/s etc...? I try to analyse how it started and how it was nurtured. Then, I concentrate on the painful and more aversive experiences. I look for pointers that lead to aversion or non-availability of a partner." (38 years, male, Psychiatrist, Pune) 
Table 4:

Perceived causes of homosexuality as reported by health care providers $(\mathrm{N}=18)$

\begin{tabular}{|c|c|c|}
\hline Causes & $\begin{array}{l}\text { Number of } \\
\text { respondents }\end{array}$ & \\
\hline \multicolumn{3}{|l|}{ Environmental Factors } \\
\hline Early exposure & 7 & $\begin{array}{l}\text { - Accidental sexual exposure/sexual } \\
\text { exploration/sexual abuse by person of the } \\
\text { same-sex was the first sexual experience, } \\
\text { which was pleasurable } \\
\text { - Habit formation of same-sex attraction }\end{array}$ \\
\hline Same-sex spaces & 8 & $\begin{array}{l}\text { - Hostels } \\
\text { - Army/Navy } \\
\text { - Truck drivers } \\
\text { - Prison } \\
\text { - Culturally not allowed to mingle with the } \\
\text { opposite sex } \\
\text { - Lack of choice or exploration } \\
\text { - Peer pressure or incidents of ragging. }\end{array}$ \\
\hline $\begin{array}{l}\text { Negative feelings towards } \\
\text { the opposite sex }\end{array}$ & 2 & $\begin{array}{l}\text { - Negative attitudes towards heterosexuality } \\
\text { - Negative feelings or a deep-rooted conflict } \\
\text { with the opposite sex }\end{array}$ \\
\hline $\begin{array}{l}\text { Early childhood } \\
\text { experiences }\end{array}$ & 1 & $\begin{array}{l}\text { - Upbringing among/along with several girls } \\
\text { (Specifically mentioned in the context of a } \\
\text { male homosexual) }\end{array}$ \\
\hline $\begin{array}{l}\text { Other environmental } \\
\text { factors }\end{array}$ & 4 & $\begin{array}{l}\text { - Lack of sex education } \\
\text { - Same-sex act under the influence of } \\
\text { alcohol } \\
\text { - Same-sex act for buying drugs or for } \\
\text { money } \\
\text { - To try out something new } \\
\text { - Poverty } \\
\text { - Lack of emotionally nurturing environment } \\
\text { in the family }\end{array}$ \\
\hline Biological & 2 & $\begin{array}{l}\text { - Genetic/inborn } \\
\text { - Hormonal }\end{array}$ \\
\hline
\end{tabular}

Note: The number of responses is $>n$ due to multiple responses.

"If I have a client whose father is a much older man and has married a young woman (the boy's mother), and if they do not have a good marriage and the boy has a lot of pity and sympathy for the mother and disgust for the father and, therefore, turns towards men, then I would try to create ambivalence. I would tilt him to feeling positive towards his father and help him identify with his father. Also, if there is a heterosexual relationship in this person's life or such a relationship has been attempted, I would try to strengthen it." (50 years, male, Psychiatrist, Pune) 
All the health care providers seemed to think that environmental factors were responsible for homosexuality; only two attributed it to both biological and environmental factors. Those who viewed same-sex orientations as resulting from environmental factors such as abuse and exploitation were inclined to believe that homosexuality or same-sex desire could not be a 'choice' and was often, "learnt" behaviour which could be "unlearnt" through therapy.

While these statements indicate the acceptance of homosexuality as a normal variant of sexuality and not an abnormality, these heath care providers (as we shall see later, in the section on "Enhancing heterosexual sexual performance") mainly used sex therapy to treat the client's clinical symptoms of sexual dysfunction, in the context of his marital relationship, ignoring thereby, his concerns with regard to his sexual identity and related issues.

\section{'Superficial' homosexuality}

Four health care providers based their decision to administer conversion therapy on what they termed as 'superficial' homosexuality. They stated that these individuals had come to 'believe' that they were homosexual though in reality they were not. Hence, the providers were of the opinion that if adequately motivated, such 'superficial' homosexuals could overcome their homosexual behaviour. Conversely, five health care providers spoke of a concept variously labeled as a 'true' homosexual, 'classic' homosexual or 'pakka' [fixed] homosexual. Such individuals, they claimed, did not warrant conversion therapy.

"Actually, I have seen 10-15 people but they are not all classic homosexuals. There is a difference! If the person has not had intercourse and it's only attraction, then he is not a classic homosexual. There are two types, one is a classic homosexual and the other is one who thinks he is a homosexual. Classic homosexuality is not a disorder, it's normal. The other kind or person who thinks he is homosexual and has a typical history. Every patient of this kind that I have seen has had some kind of experience in childhood. I mean an elder brother or an uncle or a cousin has done something sexually to the person who has not been oriented since and has come to believe that this [homosexual behaviour] is the right thing and continued with it. He is not homosexual but he has been doing the same thing since childhood... like he would have masturbated his brother or something like that ....But there is no anal intercourse, only superficial acts have been performed and the person thinks he is homosexual. But actually, he can be shifted to normal sexuality. I would tell him how a homosexual is...theoretically. Then I would tell him that a homosexual does such-and-such a thing; you don't have those traits and so, you are not a homosexual. Therefore, you can change..." (32 years, male, Psychiatrist, Pune)

This health care provider seemed to believe that 'classic' homosexual behaviour was characterised by anal intercourse alone, and could not be cured. According to him, any other form of sexual expression implied 'superficial homosexuality' which was amenable to treatment and hence an indication for using conversion therapy.

Another health care provider, however, perceived that having multiple partners in a homosexual relationship suggested that the person can be easily converted to 
heterosexuality. He explained that such a client was unlikely to be emotionally attached to any one partner and, therefore, his multiple partners could be readily replaced by a woman.

"There are a lot of them [homosexuals] where it is only one-to-one like a love affair between a man and a woman. In such a case, it becomes very difficult for the person to get out of it. If the attachment is with one guy/friend only, it can be difficult, but if there are already many partners, they can easily be substituted by a woman." (32 years, male, Psychiatrist, Pune)

\section{Adequate motivation to change}

That the motivation possessed by the client to change his/her sexual orientation contributes significantly to the success of conversion therapy was a view shared by the majority of the health care providers (15 of the 18 respondents who were interviewed) and was, therefore, an important criterion used to select clients for conversion therapy. For example:

"I first check for the person's motivation. Only if he wants to stop this then it can work... I have both pre-marital and post-marital cases such as cases wherein a homosexual wants to get married and when he is already married. I tell the patient as well as the family that this may work only if he is motivated and determined [to change]..." (52 years, male, Sexologist)

"Well, I tell them that I am ready to give it a try. But, it would require your determination. It may take years together and for all you know, it may never happen...” (60 years, female, Sexologist, Pune)

One of the health care providers who was involved in a study aimed at helping young priests to give up homosexual behaviour corroborated their views:

"I was working on this study with young priests who had homosexual behaviour and wanted to get rid of it because their profession didn't allow it. Basically, their urge to give it up was very strong because they were priests and their homosexual behaviour had resulted from a few instances of sexual abuse. What we largely used for behaviour change was the concept that homosexuality is not parallel to their profession. This worked for them and they came out of it!" (34 years, male, Psychiatrist, Mumbai)

Ten health care providers reported that they informed both the patient and his/her family members that a change toward heterosexuality is possible if the person possess sufficient motivation to change. They also cautioned that it could take a long time and may not necessarily occur.

Overall then, all the 18 health care providers affirmed that conversion therapy was warranted in those individuals who were diagnosed as ego-dystonic, those whose homosexuality was diagnosed to have been caused mainly by environmental factors, those who were diagnosed as 'superficially' and not 'really' homosexual, and those who possessed adequate motivation to change their sexual orientation. 


\section{What are the methods used?}

Several methods to change the sexual orientation of homosexual persons emerged from the interviews. Psychiatrists, by and large, reported the use of interventions such as heterosexual imagery, fantasy building, creative visualisation and cognitive behaviour therapy. On the other hand, most of the other health care providers employed methods such as "giving advice" on how to curtail "such behaviour". The treatment administered by a small number of health care providers (five) was limited to treating the symptoms of sexual dysfunction presented by the client in the context of his marital relationship and improving heterosexual behaviour and sexual performance.

\section{Fantasy building}

Techniques of imagery, fantasy building and creative visualisation are based on learning theories that have been widely used in behaviour therapy. The primary assumption of these techniques is that homosexuality is a learnt or acquired behaviour wherein the person has learnt to associate pleasure, specifically sexual pleasure, with a person of the same sex. This may have occurred due to the person having experienced same-sex sexual contact and found it pleasurable. Different health care providers described various techniques such as creative visualisation, fantasy building, and imagery to help the person to break this pleasurable association with same-sex contact and form a new association between sexual pleasure and opposite-sex contact.

In addition to these techniques, these health care providers prescribed certain ground rules that the patient was expected to follow during the course of the therapy such as, "no fantasising about the same sex", "no keeping in touch with past lovers" and complete cessation of same-sex sexual acts. Narratives describe the exercises of fantasy building and creative visualisation used by the health care providers:

"I use imagery wherein a homosexual image is shown and the person is asked to masturbate. Then, during masturbation, just before ejaculation, when there is ejaculatory inevitability, the image is replaced with a heterosexual image. It can either be done in the mind or on screen. If the person has any heterosexual relationship in his life, I try to make it healthier. I would use her [the heterosexual partner] as a co-therapist. I would try to find out why the person has developed this alienation... this disgust for the other sex...” (50 years, male, Psychiatrist, Pune)

“...I believe that [in normal circumstances] there is libido which flows [in a certain direction]; for homosexuals, it flows in the wrong direction. So, the first step is to make the patient stop everything that has to do with his sexual life. Basically, his libido has to stop flowing in that [homosexual] direction. Therefore, I make him abstain from all activities that have anything to do with homosexuality; even fantasising about homosexual sex has to stop. As a result, the patient is deprived [of homosexual contact/fantasy], his libido builds up to a point when it seeks 
release. At that point, the patient is shown heterosexual images or arousal stimuli. Then, he can be changed to a heterosexual..." (38 years, male, Psychiatrist, Pune)

".... Another thing that I do is ask the person to buy a magazine and whenever he sees a man's photo, to just ignore it and go ahead. Then, find a woman's photo... look at it. Do you like her? If you like her, what do you like about her? Oh, her figure is wow! OK, cut it out and keep it aside. Go to the next picture - what do you like in this woman? Her lips? OK. Cut it out and keep it. I ask him to repeat this till he has cut out 30 pictures and then come back to see me. So, in this way, I have already made him begin to focus on females, I have started making him look for beauty in females. In addition, he will start looking for females on TV and later, he will start doing it continuously. Basically, he hasn't been paying attention to women at all. Then, I will ask him to pick out three top women from those pictures and put them into a fantasy theme. For example, if he has liked the picture of Madhuri Dixit [a famous film actress in India] because she is pretty, I will start off by saying, 'Imagine it's a Sunday and you are alone at home. OK? You are totally relaxed and the bell rings. You open the door and see Madhuri Dixit standing there smiling at you. You are shocked! She tells you that till tomorrow morning she is going to be with you and you can do whatever you want with her... you can take her to the movies, you can sleep with her, you can touch her wherever you want... So, basically, you have 24 hours with her. Now, tell me, what will you do in these 24 hours?' Then the patient starts imagining and talking, and I keep nudging him to make it [his narrative] more erotic. Then, I ask the patient to repeat this every day and then, eventually, to start masturbating. Keep practising this exercise...” (48 years, male, Sexologist, Mumbai)

"I use creative visualisation in which the person gets very intimate with a woman, and tape it so that he can hear it all the time. Basically, fantasy life is very short; therefore, we use visualisation. When he begins to feel very comfortable, you begin to build a story [about the patient and the woman] saying, 'You are holding hands and you are aroused by the touch.' You have to create a Mills and Boon story for him. This takes time and he has to walk with you. The results are uncertain..." (53 years, male, Psychiatrist, Mumbai)

\section{Advice giving}

Six of the 18 health care providers offered advice about what the client should or should not do in lieu of conversion techniques in order to effect a change. For example: "avoid thoughts [of same-sex]" or "think of the same-sex person you are attracted to as your brother or sister" or merely telling the person that "this is not acceptable and is causing problems like STDs; so change your habits."

A dermatologist from Pune said,

"I ask them: 'Why do you need to do it? What do you feel? You have the same [implies body parts] as they have, so what is attracting you?' I always tell them to try and avoid [such behaviour], to divert the mind. I say, 'If you are attracted to a person, you should think of the person as your brother or sister, whoever the 
person may be.' We say: 'No... Keep control!...' I tell them that it [homosexuality] is still not accepted here... I don't give any medication, just tranquilisers to calm the mind because they keep thinking about this thing only..." (28 years, male, Dermatologist, Pune)

The purpose of therapy as reflected in these two quotes is to enhance heterosexual behaviours and the tool for doing so is 'advice'. Most dermatologists and gynaecologists who were interviewed reported that they practiced such advice-giving as a method of conversion possibly because they were not trained in the specific behavioural techniques used by psychiatrists and sexologists. Nonetheless, the quotes reflect provider opinions endorsing the deviancy view of homosexuality.

Another psychiatrist who used imagery during masturbation also reported that he advised his clients thus:

"If the patient is bisexual, he finds both acts pleasurable. So I tell him to try and increase attraction towards the opposite sex and reduce same-sex attraction. I know it can't be zero percent, but at least to try and make it 75-25, 75\% towards the opposite sex and $25 \%$ towards the same sex. I tell him to increase attraction towards his wife. This is the ideal situation but if it is not possible, to enjoy both! But he should keep a partition between the two; that is the practical way to be. In the case of a bisexual person, there is a very good chance of increasing libido to increase attraction for the opposite sex...” (32 years, male, Psychiatrist, Pune)

Although this provider did not advise the complete cessation of homosexual behaviour, he did give a message about the desirability of enhancing heterosexual contact and relationships in the client's life and the reduction of homosexual attraction.

\section{Enhancing heterosexual sexual performance}

Five of the 18 health care providers who practiced conversion therapy spoke about helping the homosexual client to deal more effectively with problems related to sexual performance in a heterosexual relationship. In some cases, the reason for consultation was the client's desire to be able to marry, though more often, it occurred when the homosexual person attained marriageable age or if he/she had a marital problem.

For example:

A sexologist from Pune who gives many public lectures and writes about marital sex had this to say about his experience with homosexual clients:

"In premarital cases, many have got involved and are engaged in homosexual activities. They need to dissociate themselves from that before marriage and learn to develop heterosexual fantasies and techniques which I teach them. In post-marital cases, the objective is to make the person comfortable with the idea of foreplay and postures during intercourse. I would guide him in developing and being comfortable with the idea of heterosexual sex.” (52 years, male, Sexologist, Pune) 
For married homosexual men, the treatment of sexual dysfunction involved the use of various therapeutic measures such as hormones, drugs and surgery to induce artificial erection so that the client could consummate his marriage or perform the procreative function, or to improve the quality of sexual performance as the following quotes indicate:

"Sometimes, people have to get married under pressure... They come to me asking for help so that they can have sex just once with their wife. Just so that they can have a child. They literally beg me to do something, just once. In such a case, I provide hormonal therapy. Maybe create an artificial erection by giving a papaverine injection in the penis. I would tell the person to imagine that he is having anal sex with his partner so that he can have sex [with his wife]... Many of them return to show me their children..." (smiles) (49 years, male, Psychiatrist, Mumbai)

"We do counselling, we give medication, hormonal injections - sildenafil, trimix and papaverine injections, and tadanafil in severe cases. These are used for artificial erection. I have also given implants to two of my patients..." (46 years, male, Urologist, Pune)

A health care provider in Mumbai spoke about married homosexual men approaching him for treatment of sexual impotence in the marital context:

"If the person is married... basically, early in the morning, when you get up, there is a fine, good quality erection because of hormonal cycles. So, we ask him to have sex at that time, if it is possible." (45 years, male, Psychiatrist, Mumbai)

Although these practitioners did not actively seek to convert the sexual orientation of their clients through the use of conversion techniques, the basic framework of the treatment they administered remained the same in that they used sex therapy to combat sexual dysfunction in their clients and help them to achieve successful heterosexual performance.

The above quotes indicate that these health care providers, including psychiatrists and sexologists, restricted the focus of their therapy to the clinical symptom of sexual dysfunction within the framework of a conventional marriage, while completely ignoring sexual identity and related issues. However, in helping both unmarried and married clients to improve their heterosexual expression, issues such as dealing with the pressure to marry or finding out whether or why a homosexual person wanted to get into a heterosexual marriage were not addressed. Likewise, other health or mental health needs of married homosexual men, their spouses or same-sex partner/s apparently remained unaddressed. 


\section{What defines successful therapy?}

While conversion, by definition, aims at changing homosexual orientation, most of the health care providers interviewed focussed on 'conversion of behaviours' and, in many cases, their aim was not really conversion but the 'learning of new/heterosexual behaviours' by their clients.

Thirteen of the 18 health care providers claimed to have cured "many" homosexuals. Most of them defined "success" or "cure" in terms of the client getting married or reporting a happy marriage or returning to show them his/her baby. Thus, the treatment was deemed successful if the client was able to have heterosexual sex, get married and procreate, if married thereby reflecting the cultural emphasis on male sexual performance. Significantly, their assessment of successful conversion from homosexuality to heterosexuality did not touch on homosexual desires or behaviours and/or their reduction or cessation following therapy.

"Many of them return saying that I am happy. They say things like they do not have those [homosexual] thoughts anymore and are able to enjoy with their wives. But, I don't believe that they have stopped anything. They must be continuing with whatever they were doing. It's just that they are not anxious and they are happy. Anyway, they have got the concept. They become more or less bisexual. They start enjoying both the sides...” (45 years, male, Psychiatrist, Mumbai)

"Success is difficult to measure... See, basically, they are deviants and then they get married and these are success stories. Once the treatment is successful, they stop coming to me. And, even if it is unsuccessful, they stop coming; they may go elsewhere... so one really can't say...” (60 years, female, Psychiatrist, Pune)

In both these quotes, the health care providers while describing successful conversion of same-sex sexual orientation have limited their definition to the occurrence of heterosexual contact/s or marital status and not the cessation of homosexual behaviours. In fact, as one of the health care providers (male psychiatrist from Mumbai) stated that homosexual activity may be ongoing furtively and may not be reported by the client during follow-up visits.

Three of the health care providers also talked about treatment failures that they had encountered and possible reasons for such failures.

"I have had almost 100\% success with very few exceptions... In the bisexual group, people come with motivation. Only three cases failed even after counselling. He had some psychological block. Such cases were referred to a psychiatrist. He was obsessed with his homosexuality. He was repeatedly getting involved in homosexual activity. I couldn't help two or three cases. Their motivation [to change] was not adequate....." (52 years, male, Sexologist, Pune) 
"Perhaps with counselling and psychiatric help, you can control it, but I haven't seen anyone who has been successfully treated. It is like any other mental problem. There is no total cure. Lifelong treatment and regular follow-up is needed..."

(25 years, male, Dermatologist, Mumbai)

The health care providers' responses to the question of failures encountered in the course of their efforts to convert their clients underscore the point that the client's motivation to change is the key to successful conversion. Thus, treatment success or failure is dependent to a large extent on the patient's own will. Furthermore, the two quotes above equate homosexuality with psychiatric disorder, the first describing homosexual preference/ desire as 'obsessive' and the second equating homosexuality with chronic mental disorders that require lifelong treatment. Overall, it seemed that the health care providers neither followed any clear-cut guidelines or criteria for treatment success or efficacy nor did they mention any specific tool or measure for ascertaining success. 


\section{Discussion}

This study has shown that despite the fact that international psychiatric circles no longer consider homosexuality as a mental illness or an abnormality, almost half of the health care providers we interviewed in Mumbai and Pune often treat it as a deviation or mental health problem that should be changed to a heterosexual orientation. By subscribing to this view, these practitioners do not appear to deal with the issues of stigmatization, discrimination and other stressful social experiences that may be important contributors to the individual's health or mental problems. On the other hand, three of the health care providers who had ever used conversion therapy reported a change in their practice with homosexual clients in that they completely gave up conversion therapy because they had reservations about its efficacy and did not consider it "right to treat homosexuality per se.” The other half of our respondents, however, took a different approach to dealing with homosexuality in that they treated the symptoms for which the individual had approached them and/or supported the individual and his/her family to accept his/her homosexuality. Interestingly, five of them stated that looking for a cause for homosexuality was irrelevant as homosexuality was as natural as any other sexual orientation or behaviour.

Among the health care providers we interviewed, an almost equal number of those who practiced conversion therapy attributed the 'condition' of homosexuality to child sexual abuse or early sexual initiation and exploration $(\mathrm{N}=7)$ or to a lack of exposure to the opposite sex while living in 'male-only' environments $(\mathrm{N}=8)$. Thus, it appears that these health care providers considered same-sex sexual orientation to be partially or wholly 'caused' by or 'learnt' through adverse environmental factors and hence amenable to change. A similar perspective can be seen in older psychoanalytic literature in which homosexuality was considered to be pathological sexualisation and therefore in need of 'repair' (Nicolosi, 1991).

While the rationale for treating homosexuality was 'environmental causation', the treatment focused on 'individual behaviour', thus locating the problem within the 'homosexual client' and placing the responsibility of assuming a heterosexual orientation also on the individual 'homosexual client'. Several of the health care providers communicated to the homosexual client as well as family members that the success of their interventions was dependent on the client's motivation to change and that there was no guarantee of success. This implies that the onus of the success or failure of the therapy lies entirely on the homosexual client. Further, the client also suffers pressure from both his/her family and health care provider to change and to report the success of the treatment. This makes self-reporting of the success of conversion therapy, which according to the health care providers was the only criterion of measuring the efficacy of their treatment - a questionable proposition.

Half of the health care providers we interviewed continued to use conversion therapy, the theoretical foundations as well as effectiveness of which are questionable (Haldeman, 1994). A recently published systematic review of 28 empirically-based, peer-reviewed full 
length articles and brief reports addressing the efficacy of reparative therapies (Serovich et al, 2008) shows that most of these studies are methodologically flawed. The limitations include the lack of a theoretical base to the interventions carried out, inconsistent definitions and measurement of sexual orientation, restricted samples and lack of followup. In terms of what constitutes change, most of these research studies focused on sexual acts or behaviours. Even in the current study, many health care providers defined success of treatment in terms of heterosexual performance, including getting married plus successful procreation. However, same-sex sexual orientation/ preference does not imply sexual impotence or a complete inability to engage in peno-vaginal sex. Moreover, sexual orientation goes beyond sexual behaviours and consists of several dimensions including sexual desire, sexual preference, and affectional and relational components. Therefore, such criteria of 'success' of treatment for 'homosexual orientation' are debatable.

Some studies have described negative outcomes of the use of conversion therapies, including resulting chronic depression, low self-esteem, difficulty in sustaining relationships and sexual dysfunction (Haldeman, 2002). Shidlo and Schroeder (2002) noted that a majority of those who sought reparative therapy perceived psychological harm in the form of depression, suicidal ideation and attempts, social and interpersonal harm, loss of social support and spiritual harm as a direct result of the interventions. In a study conducted by Smith et. al. (2004) in the United Kingdom, 29 individuals and two relatives of former patients who had received therapy for their homosexuality from the 1960s to the 1980s were interviewed to understand the circumstances in which people sought therapy, referral pathways, the process and aftermath of the therapies. No participant thought he/she had benefited from the therapy and for many it increased their sense of social isolation and shame, and lowered their sense of self-worth. The study concluded by cautioning against the use of mental health services to change aspects of human behaviour that are disapproved of on social, political, moral or religious grounds.

Mental health practitioners such as Haldeman (2002) have also reported that the practice of sexual reorientation therapy socially devalues homosexuality and bisexuality. Moreover, many of these conversion therapies approach the whole issue of homosexuality in a vacuum with no regard to the homophobic social attitudes in which individuals with same-sex desires live out their lives. Thus, the use of conversion therapy for changing sexual orientation is fraught with several problems.

Some of the other issues raised by the health care providers' responses in the sections on "What defines successful therapy?" and "Enhancing heterosexual sexual performance" concern the 'compulsory' nature of heterosexual marriage in Indian society and the cultural links of masculinity and manhood with the man's ability to procreate. Some of them also seemed to subscribe to this normative thinking and hence provided various medical solutions for consummation of marriage and procreation to the married homosexual. Interestingly, some responses of the health care providers in these same sections also hint at the acceptability of sex 'outside marriage' for married homosexual men as long as the duties of heterosexual marriage and procreation are fulfilled.

Thus, it seems that despite conversion therapy falling short both on standards of efficacy as well as ethics, in reality there would always be people who would seek help for 
'unwanted' same-sex attractions. The reasons for such help-seeking may include social and familial factors such as pressures to marry or the individual's own desire for socio-legal recognition through heterosexual marriage or embracing an overtly heterosexual lifestyle. Reasons for seeking change in orientation may also include such factors as internalised homophobia, shame, fear, anxiety, confusion and so on. In fact, literature on lesbian/gay identity development indicates that most lesbian/gay individuals go through several stages of identity development before they reach identity synthesis, wherein they are at peace with themselves. Some of these stages include identity confusion, identity comparison, tolerance, acceptance, pride, synthesis. The stage of identity confusion, for instance, is especially relevant here as it is characterised by internal conflict, attitudes that homosexuality is incorrect and undesirable, explaining away same-sex attraction and so on (Cass, 1979 in Ritter et al, 2002). An individual struggling through this stage may often present in clinical situations as a 'ego-dystonic homosexual' and if this developmental struggle is not seen in the context of peer, familial, social pressures then he/she may get diagnosed as a 'ego alien' or 'ego-dystonic' homosexual. The need to understand the concerns of young homosexual individuals in the Indian socio-cultural context with strong family bonds and rather rigid ideas of 'compulsory' marriage is being highlighted here. Similarly, that the Indian legal system that continues to see homosexuality as a criminal offence leads to police harassment and augments stigmatisation cannot be ignored while making sense of individuals' journeys of sexual identity development and their helpseeking attempts for their homosexuality. Under these circumstances, continuing to treat clients with a perspective of 'reparation' and 'conversion' to heterosexuality raises serious ethical concerns.

In the Western countries, increased efforts are being made to draw linkages between the social marginalisation of sexual minorities and its impact on health outcomes. Lesbian and gay affirmative therapy is one such outcome. Here, the emphasis of therapy is to understand the client's discomfort with his/her sexual orientation as resulting from internalised and external homophobia. Thus, the social and psychological context of discomfort assumes more importance than the clinician's theoretical perspective on sexual orientation or either type of sexual reorientation therapy (Haldeman, 2002). The American Psychological Association (2000), the National Association of Social Workers (1992), and the American Counseling Association (Whitman, Glosoff, Kocet et al in Serovich et. al, 2008) have specific, detailed guidelines for psychotherapy with gay, lesbian and bisexual clients. These guidelines broadly state that clinicians should understand that homosexuality or bisexuality is not a mental illness and that the clinician's attitude towards homosexuality could easily reflect in his or her therapy. Therefore, they need to be free of prejudice and judgement. The guidelines also mention that the stigmatisation that a gay or lesbian person faces, poses a risk to his or her mental health and well being and that it must be taken into consideration during diagnosis and therapy. Regardless of the treatment focus, anything less than an affirmative stance in which individuals are treated with positive regard can further undermine their self-esteem. 


\section{Summing up and recommendations}

\section{Summing up}

In contrast to most international guidelines for treatment of homosexuality, conversion therapy for homosexuality still seems to be practiced by many health care providers in India. Findings suggest that health care providers' attitudes, understanding and assumptions regarding normative and non-normative sexuality, homosexuality, marriage, procreation and change or cure of homosexual sexual orientation makes up a complex belief system that has not incorporated some of the latest international health and human rights perspectives. Findings also suggest that a few health care providers reported a change in their practice with respect to homosexuality as a response to changes in the social and medical understanding of same-sex desires over time. The social, political and legal contexts of same-sex desires in India intersecting with the realities of class, caste, gender and other factors makes the lived experiences of individuals with same-sex desires extremely complex.

\section{Recommendations}

Given the ambiguities in provider perceptions and experiences regarding conversion therapy that emerge from the findings of this report, there is an urgent need to integrate some of the guidelines and models of 'affirmative therapy' used in the West into clinical practice in India. Findings suggest the need :

- To help professionals to be alert to the complexities of homosexual sexual orientation and not respond out of personal prejudices or lack of knowledge

- To dialogue with national and international medical training institutes as well as medical professional bodies

- To review the existing medical curriculum, both graduate and post-graduate training, in different branches of medicine to understand current levels of knowledge and approaches concerning 'homosexuality'

- To incorporate a multidimensional understanding of homosexuality and associated health/mental health issues

- To set up consultations of various health professionals to review the guidelines for 'affirmative therapy' available in international literature and adapt them (where appropriate) in the Indian context

- To include representations of researchers, academicians and activists working on issues relating to sexual minorities to be a part of the above-mentioned review processes. 


\section{References}

American Psychiatric Association (APA). 1952. Diagnostic and Statistical Manual of Psychiatric Disorders (DSM). Washington, APA.

American Psychiatric Association (APA). 1973. "Position Statement on Homosexuality" in Comprehensive Textbook of Psychiatry, Volume I (7th Edition), ed. B.J. Sadock and V.A. Kaplan. Lippincott Williams \& Wilkins.

American Psychiatric Association (APA). 1987. Diagnostic and Statistical Manual of Mental Disorders - DSM III-R. Washington, APA.

American Psychiatric Association (APA). 1998. "Position Statement on psychiatric treatment and sexual orientation,” American Journal of Psychiatry (APA). 1999; 156:1131, <www.psych.org/edu/other_res/ lib_archives/archives/ 980020.pdf>

American Psychiatric Association (APA). 2000. "Position Statement on Therapies Focused on Attempts to Change Sexual Orientation (Reparative or Conversion Therapies)”. APA, May, <http://archive.psych.org/edu/other_res/ lib_archives/archives/ 200001.pdf $>$ accessed on 28 August 2007.

American Psychological Association (APA). 2008. "Answers to Your Questions: For a Better Understanding of Sexual Orientation and Homosexuality,” Washington, DC: $<$ www.apa.org/topics/sorientation.pdf $>$.

Cass, V.C. 1979. "Homosexual identity formation: A theoretical model.” Journal of Homosexuality, 4:219-235.

Chandran, V. 2006. "Prayer, punishment or therapy? Being a homosexual in India," InfoChange News \& Features, February. <http://www.infochangeindia.org/ agenda4_24.jsp> accessed on 28 August 2007.

Drescher, J. 1998. “I’m your handyman: A history of reparataive therapies.” Journal of Homosexuality 36 (1): 19-42. <DOI: 10.1300/J082v36n01_02> accessed on 25 June 2008.

Economic and Political Weekly. 2008. "Section 377 and Denial of Rights to Sexual Minorities.” 25 October. South Asia Citizens Web. 30 October 2008.

$<$ http:// www.sacw.net/article198.html>

Haldeman, D.C. 1994. "The practice and ethics of sexual orientation conversion therapy," Journal of Consulting and Clinical Psychology, 62(2): 221-227.

Haldeman, D.C. 2002. "Gay rights, patient rights: The implications of sexual orientation conversion therapy,” Professional Psychology: Research and Practice, 33(3): 260-264. 
Halpert, S. 2000. "If it ain’t broken, don’t fix it: Ethical considerations regarding conversion therapies," International Journal of Sexuality and Gender Studies, 5(1): 19-35.

Herek, G.M. 1996. "Heterosexism and homophobia," in Textbook of Homosexuality and Mental Health, ed. R.P. Cabaj and T.S. Stein. Washington, DC: American Psychiatric Press, pp. 101-113.

Herek, G. 1999. "'Reparative Therapy”" and other attempts to alter sexual orientation: A background paper.” 5 November, <http://psychology.ucdavis.edu/rainbow/html/ facts_changing.html>

Hooker, E. 1957. "The adjustment of the male overt homosexual," Journal of Projective Techniques, 21(1): 18-31.

International Commission of Jurists (ICJ). 2007. "Yogyakarta Principles - Principles on the application of international human rights law in relation to sexual orientation and gender identity.” Available at: http://www.yogyakartaprinciples.org/

Joseph, S. 1996. "Gay and lesbian movement in India," Economic and Political Weekly, 31: 2228-2233, August 17.

Katz, J. 1976. Gay American History: Lesbians and Gay Men in the U.S.A.: A Documentary Anthology. New York: Crowell, p. 129.

Morrow, S.L. and A.L. Beckstead. 2004. "Conversion therapies for same-sex attracted clients in religious conflict: Context, predisposing factors, experiences, and implications for therapy,” The Counseling Psychologist, 32:641-650.

Murphy, T. 1992. "Redirecting sexual orientation: Techniques and justifications.” Journal of Sex Research, 29: 501-523.

Narrain, A. 2002. "Medicalisation of homosexuality.” Available online $<$ http://www.combatlaw.org/information.php? Article_id21\&issue_id=1> accessed on 10 March 2008 [Vol.1, Issue 1, Mar-April 2002].

Nicolosi, J. 1991. Reparative Therapy of Male Homosexuality: A New Clinical Approach. Northvale, NJ: J. Aronson.

Nicolosi, J., A.D. Byrd and R.W. Potts. 2000. "Retrospective self-reports of changes in sexual orientation: A consumer survey of conversion therapy clients,” Psychological Reports, 86:1071-1088.

Parekh, S. 2003. "Homosexuality in India: The light at the end of the tunnel," Journal of Gay \& Lesbian Psychotherapy, 7 (1/2): 153.

People’s Union for Civil Liberties-Karnataka Chapter (PUCL-K). 2001. Human Rights Violations Against Sexuality Minorities in India. A Fact-finding Report about Bangalore. A Report of PUCL-Karnataka, February. 
Pradhan, P.V., K.S. Ayyar, and V.N. Bagadia. 1982. "Homosexuality: Treatment by behavior modification,” Indian Journal of Psychiatry, 24(1): 80-83.

Ranade, K. 2003. "Stigma, stress and coping among gay, lesbian, bisexual individuals - A qualitative study." Dissertation submitted in partial fulfilment for MPhil in Psychiatric Social Work, NIMHANS (Unpublished).

Serovich, J.M., S.M. Craft, P. Toviessi et al. 2008. "A systematic review of the research base on sexual reorientation therapies." Journal of Marital and Family Therapy, 34(2):227-238.

Shidlo, A. and M. Schroeder. 2002. "Changing sexual orientation: A consumers' report," Professional Psychology: Research and Practice, 33: 249-259.

Smith, G., A. Bartlett and M. King. 2004. "Treatments of homosexuality in Britain since 1950s - An oral history: The experience of patients," British Medical Journal, 328:427-9.

The Times of India. 2006. "Govt's AIDS cell pushes to legalise homosexuality.” Delhi Edition. TNN, 20 July. http://times of india.indiatimes.com/articleshow/msid-1779097, prt page-1.cms

Throckmorton, W. 1998. "Efforts to modify sexual orientation: A review of outcome literature and ethical issues," Journal of Mental Health Counseling, 20: 283-305.

Throckmorton, W. 2003-2004. "What is reparative therapy?" accessed on 21 March, 2007.http://www.drthrockmarton.com/article.aspid=4

Tozer, E.E. and M.K. McClanahan. 1999. "Treating the purple menace: Ethical considerations of conversion therapy and affirmative alternatives," The Counseling Psychologist, 27: 722-742.

Vanita, R. and S. Kidwai. 2000. Same-Sex Love in India: Readings from Literature and History. Macmillan India Ltd.: Delhi.

Voices Against 377. 2005. Rights for All: Ending Discrimination against Queer Desire under Section 377. A compilation by Voices Against 377, Delhi.

Whitman, J. S., H. L. Glosoff, M. M. Kocet et al. 2006. Ethical issues related to conversion or reparative therapy. Cited in Serovich, J.M., S.M. Craft, P. Toviessi et al. 2008. "A systematic review of the research base on sexual reorientation therapies." Journal of Marital and Family Therapy 34(2): 227-238.

World Health Organization (WHO). 2002. ICD-10 Classification of Mental and Behavioural Disorders. Geneva: WHO.

Yoshino, K. 2002. “Covering.” Yale Law Journal 111: 769, 772-73. 


\section{Acknowledgments}

Several people provided valuable assistance during the course of this study. I would like to thank Yogita Hastak and Sudeep J. Joseph, who worked dedicatedly as research assistants on this study and Mira Oke for training the research team. I am grateful to Pertti J. Pelto for providing valuable guidance throughout the study. I would like to place on record my appreciation to the study respondents who generously gave their time and shared their experiences. I am thankful to Bapu Trust, Pune for enabling me to undertake this research and housing the project within their premises.

I would like to thank Shireen Jejeebhoy, K.G. Santhya, Shveta Kalyanwala and Komal Saxena at the Population Council for their guidance throughout the study and on previous versions of this report. I am grateful to Pertti J. Pelto and Radhika Chandiramani for reviewing the report and to Jyoti Moodbidri for editorial contributions and careful attention to detail which have made the report more readable and clear. 
